\title{
Narsisistik Kişilik Envanteri-13 (NKE-13)'nin Türkçe Geçerlik ve Güvenirlik Çalışması
}

\author{
DOI: 10.26466/opus.635725 \\ * \\ Uğur Doğan * - Tuğba Seda Çolak** \\ * Doç. Dr., Muğla Sıtkı Koçman Üniversitesi \\ E-Posta: ugurdogan@mu.edu.tr \\ ORCID: 0000-0001-7603-6470 \\ ** Dr. Öğr. Üyesi, Düzce Üniversitesi \\ E-Posta: tugbacolak@duzce.edu.tr \\ ORCID: 0000-0002-7219-1999
}

\section{Öz}

Bu çalışmanın amacı Gentile ve arkadaşları (2013) tarafından geliştirilen Narsisistik Kişilik Envanteri13 (NKE-13)'nin Türk kültüründeki psikometrik özelliklerini ortaya koymaktır. Ölçeğin uyarlama çaıışması için Muğla Sıtkı Koçman Üniversitesinin çeşitli fakültelerinde öğrenimine devam eden 308 üniversite devam eden beliren yetişnkilik dönemindeki öğrenciler ile çalışılmıştır. Ölçeğin yapı geçerliğini belirlemek için ilk önce Doğrulayıcı Faktör Analizi (DFA) yapılmıştır, daha sonraki aşamda ise ölçeğin iç tutarlılık katsayısının belirlenmesi için Cronbach Alpha katsayısı Jamovi programı kullanılarak hesaplanmıştır. DFA sonucuna göre orijinal ölçekte de olduğu gibi, ölçeğin 3 faktörlü yapısı (liderlik/ otorite, grandiyözitel gösterişçilik, hak iddia etmel sömürü) elde edilmiş ve elde edilenyapıya ilişkin ilişkin uyum indekslerinin iyi sonuç verdiğgi görülmüştür ( $\chi 2=130, d f=60, \chi 2 / d f=2.17 ; R M S E A=0,0614$, $C F I=0,938 ; T L I=0.919)$. Ölçeğin güvenirliğini belirlemek için yapılan güvenirlik analizinde ölçeğin bütünü için Cronbach Alpha içtutarlılık katsayısı .84, alt boyutlarda ise liderlik/otorite için .78, grandiyözite/gösteriş̧̧ilik için .72 , hak iddia etme/sömürü için .61 bulunmuştur. Yapılan analiz sonuçlarına göre üniversite öğrencileri için geliştirilen NKE-13 Türkçe uyarlama çalışmasının Türk kültüründe iyi sonuçlar verdiği görülmüştür. Sonuçlar ölçme aracının Türkçe uyarlamasının geçerli ve güvenilir olduğunu oltaya koymuştur.

Anahtar Kelimeler: Narsisistik Kişilik Envanteri-13, NKE-13, doğrulayıcı faktör analizi, geçerlik ve güvenirlik 


\title{
The Turkish Adaptation of Narcissistic Personality Inventory-13 Scale: The Validity and Reliability Study
}

\begin{abstract}
The aim of this study was to examine the reliability and validity of the Turkish translation of the Narcissistic Personality Inventory-13 (NPI-13). This scale was developed by Gentile et al. (2013)/ NPI-13 Scale for college students was first translated into Turkish and then back-translated. Subsequently, the questionnaire was administered to 308 college students. The internal consistency of the scale was examined for reliability, and second-order confirmative factor analysis (CFA) was conducted using Jamovi program for the validity of the scale. CFA, similar to the original scale, confirmed the fit of the 3-factor model (Leadership/ Authority; Grandiose/ Exhibitionism; Entitlement/ Exploitativeness). ( $\chi 2=130$, $d f=60, \chi 2 / d f=2.17 ; R M S E A=0,0614, C F I=0,938 ; T L I=0.919)$. The internal consistency reliability coefficient of the whole scale is .84, Leadership/ Authority is .78, Grandiosel Exhibitionism is .72, Entitlement/ Exploitativeness is .61. Our findings show that the Turkish version of the NPI-13 Scale has acceptable levels of reliability and validity for the selected samples.
\end{abstract}

Keywords: Narcissistic Personality Inventory-13, NPI-13, confirmative factor analysis, reliability, validity 


\section{Giriş}

Türkçedeki karşıllğı özseverlik olan Narsisizm (Voltan-Acar, 2012), Ruhsal Bozuklukların Tanısal ve İstatistiksel El Kitabı (DSM) 5'de kişilik bozuklukları arasında yer almaktadır. Özsever (Narsisistik) kişilik bozukluğu yetişkinlik döneminin erken safhalarında ortaya çkan, empati yoksunluğu, büyüklenme ve beğenilme ihtiyaçlarını içeren bir örüntüye sahiptir (Amerikan Psikiyatri Birliği, 2013). Bu tanımlama ile DSM 5 Psikanalitik bakış açısından uzak bir sistemi benimseyip, ruhsal sorunların anlaşılmasını biyolojik temelli çalışmalara indirgeyerek zorlaştırması konusunda eleştirilirken, Psikanalitik çalışmalar da öznellikleri nedeniyle eleştirilmiştir. Çağdaş çalışmalar Psikodinamik çalışmaların ampirik temelli ilerlemesini sağlayarak bu eleştirilerin önüne geçmeyi hedeflemiştir (Kotan, Kotan ve Özçürümez-Bilgili, 2018). Freud, benliğe yönelik narsisistik libidoyla, insanlara yatırım yapılan nesne libidosunu ayırmasıyla, bebeğin anne kucağındaki tüm güçlü olma duygusunu açıklamak için birincil narsisizm terimini ortaya atmıştır. Kendisini anneyle bütünleşik bir varlık olarak algılayan bebek, annenin yetersiz olduğu zamanlarda oluşturduğu hayal kırıklıklarıyla farklı bir varlık olduğunu anlar ve tümgüçlülük algısı zedelenir. Çocuk bu travmayla başa çıkamadığında içsel bir tüm güçlü anne temsili oluşturarak "grandiyöz kendilik" olarak adlandırılan yapının temelini oluşturur (Wallace, 2008). Narsisistik kişilikte bölme mekanizması gerçek kendilik, ideal kendilik ve ideal nesne arasındaki gerilimi ortadan kaldırmak için, bu imgelerin bir kombinasyonu olan şişirilmiş kendilik kavramı aracılığıla istenmeyen kendilik ve nesne imgelerinden uzaklaşılmasını sağlar (Volkan, 2007).

Daha sonraki dönemlerde, özellikle Freud'un takipçileri için olmak üzere, narsisizm dikkat çekici bir konu olmaya devam etmiştir. Masterson (2014) Terk Depresyonu Kuramında narsisizmi gerçek kendiliğin bozulması sonucu oluşan psikopatolojik bir savunma olarak ele alır. Çağdaş Nesne İlişkileri Kuramı olarak tanımlanan Aktarım Odaklı Terapide narsisizm, normal davranışların engellenmesi, belli davranışların abartılması gibi faktörler sonucunda ortaya çıan kişilik örgütlenmesindeki patoloji olarak ele alınır (Yeomans, Clarkin ve Kernberg, 2016). Narsisizm konusunda önemli bir isim olan Kohut (1998)'a göre ise eşduyum yetersizliği nedeniyle anne/babanın kendilik nesnesi işlevi görevini yerine getirememesi sonucu ortaya çkan primer 
narsisizmdir. Sağlıklı bir kimlik bütünlüğü için kendilik nesnesi desteği ile sekonder narsisizme ulaşmanın hedef olduğunu belirtir.

Patolojik narsisizm kırılgan, grandiyöz, açı, gizli gibi türlere ayrılmaktadır (Pincus ve Lukowitsky, 2010). DSM kriterlerine göre problemli kişilik özellikleri ya da belirtileri bilişte, duygulanımda, kişilerarası işlevsellikte ve dürtü kontrolünde olmak üzere 4 alandan ikisinde problem yaşanmasını içerir ve narsisistik kişilik özelliklerinde en sık görülen türün işlevsellikte bozulma olduğu düşünülmektedir (Miller ve Campell, 2010). Kişilerarası ilişkilerde narsisistik özelliklere sahip olma ile bağlılık arasında negatif ilişki bulunmuş ve narsisistik kişilerin ilişkide kalma süresinin kısa olduğu görülmüştür (Campbell ve Foster, 2002). Narsisistik kişilik yapısına sahip olan kişiler duygulanımda sığ bir yapıya sahiptirler ve yetersizliklerini göstermekten imtina ederler (Williams, 2013). Bilişsel şemalar üzerine yapılan bir araştırmanın sonucunda narsisizmin tetiklediği erken dönem uyumsuz şemalarının tümünün duygusal ihmal, dürtü kontrolü, bağımlılık ve kimlik oluşturma temalarıyla yakından alakalı olduğu bulunmuştur (Anlı, Can ve Evren, 2017). Erkeklerde kadınlara oranla daha yüksek düzeyde görülen narsisistik eğilimler (Aslan, Mert ve Yıldız, 2016), kardeş sayısı azaldıkça artmaktadır ve anne babası ayrı olan ergenlerin narsisistik puan ortalamaları daha yüksek bulunmuştur (Karakuş, 2017).

Son yıllarda narsisizm bir patoloji unsuru olmanın yanında bir de kişilik özelliği olarak ele alınmaya başlanmıştır (Demirci ve Eksi, 2017). Kişilik bozukluğundan, kişilik yapısını ayıran özelliklere göre Narsisistik kişilik yapısında bireyler eleştiriyi göğüsleyebilir, kişilerarası ilişkilerinde sömürücü değil, kendi amaçlarına yönelik davranır. Özel bir insan oldukları düşüncesiyle olmasa da düşüncelerini iyi pazarlarlar, yarışmayı severler ve kendilerini en başarılı olarak görürler. Eşsiz bir niteliğe sahip olduklarını düşünmelerine rağmen ayrıcalık beklemez, beğeni ve övgüyü ölçülü bir şekilde kabul edebilirler. Empati kurabilirler ve başkalarının kendilerine hep iyi davranmasını beklerler (Köroğlu ve Bayraktar, 2010). Narsisistik özelliklerin başarı isteğini artırdığı ve başkalarının baş etmekte zorlandığı, cesaret kırıcı durumlarda ayakta kalabilmelerini sağlıyor olması muhtemel bir durumdur (Lelord ve Andre, 2015). Aynı zamanda narsisizm ve benlik saygisı arasında olumlu ilişki bulunmuştur (Karakuş, 2017). Narsisizm beş faktör kişilik özelliklerinden düşük uyumluluk, yüksek atılganlık ve eğlence arama gibi özellikleri içeren dışadönüklük özelliklerine sahiptir (Miller ve Campell, 2010). 
Narsisizmi ölçmeye yönelik Türkçe çeşitli ölçme araçları bulunmaktadır. Atay (2009), Ames, Rose ve Anderson (2006)'un geliştirdiği tek boyutlu Narsistik Kişilik Envanterinin uyarlama çalışmasını gerçekleştirmiştir. 16 maddeden oluşan ölçek ikili derecelendirme türüne sahiptir ve özellikle örgütsel davranışa odaklanan normal narsisizmi ölçmektedir. Çocukluk Çağı Narsisizm Ölçeği Thomaes, Stegge, Bushman, Olthof ve Denissen (2008) tarafından geliştirilmiş, Türkçe uayarlama çalışması Akın, Şahin ve Gülşen (2015) tarafından tarafından yapılmıştır. Çocukluk çağındaki narsistik özellikleri bir kişilik özelliği olarak ölçen 10 maddelik ve tek boyutlu bir ölçektir. Ekşi (2016) klinik olmayan gruba yönelik DSM kriterlerine uygun olarak kişilik patolojisi olan narsisizmi ölçen Beş faktör Narsisizm Envanterinin kısa formunun uyarlamasını gerçekleştirmiştir. Glover, Miller, Lynam, Crego ve Widiger (2012)'ın geliştirdiği, Kırılgan Narsisizmi ve Grandiyöz Narsisizmi ölçmeye yönelik içeriğe sahip ölçek 15 alt boyuttan oluşmaktadır. Narsisistik Hayranlık ve Rekabet Ölçeği Back ve arkadaşları (2013) tarafından geliştirilmiş, Türkçe uyarlama çalışması Demirci ve Ekşi (2017) tarafından gerçekleştirilmiştir. 18 maddelik uzun ve 6 maddelik kısa olmak üzere iki formdan oluşmaktadır. Özsoy, Rauthmann, Jonason ve Ardıç (2017) Tek Maddeli Narsisizm Ölçeğini Türkçeye uyarlamıştır. Konrath, Brian ve Bushman (2014) tarafından geliştirilen ölçek 7'li Likert tipinde derecelendirme ile özbildirimle kişinin kendini ne kadar narsisistik gördüğünü değerlendirmesine dayalıdır.

Narsisizmin kişilik özelliğini belirlemeye yönelik öz bildirim formları, DSM bilgileri ışı̆̆ında hazırlanan formlar olduğu için klinik olmayan grupta yine de kişilik bozukluğuna yakın bir yapıyı ölçmektedir (Miller ve Campell, 2010). Kişilik ölçümlerinde güvenilir ve geçerli kısa formlar araştırmalardaki yeni ilerlemeleri teşvik edebileceği için çok değerli olmalarının yanında hem patolojik narsisizm hem de özsaygıdan ayrı bir şekilde normal narsisizmi ayırt eden ölçeklere (Gentile vd., 2013) ihtiyaç duyulmasından kaynaklı NKE13'ün Türkçe'ye uyarlanması önemli olarak değerlendirilmektedir. Türkçe ölçme araçlarına bakıldığında normal narsisizmi ölçen ölçek sayısı ve bu ölçeklerin bir kısmının patolojik yapı (Büyükgüngör, 2016), örgütsel yapı (Atay, 2009) gibi normal örneklemin dışındaki yapılara yönelik olması bir sınırlılık olarak değerlendirilmektedir. Demirci ve Ekşi (2017)'nin uyarlama çalışmasinda hayranlık boyutu büyüklenme, benzersizlik ve cazibe altboyutları ile rekabet boyutu ise değersizleştirme, üstünlük ve saldırganlık altboyutları ile 
DSM kriterlerine dayalı bir şekilde narsisizmin özelliklerini ölçmektedir. Ancak bütüncül bir narsisizm puanı vermiyor olması da yeni ölçme araçlarına ihtiyacı ortaya çıarmaktadır. Bu çalışma kapsamında Gentile ve arkadaşları (2013) tarafından geliştirilen Narsisistik Kişilik Envanterinin-13 (NKE-13) Türkçe'ye uyarlanması amaçlanmaktadır. NKE-13 grandiyöz narsisizmi ölçen kısa bir ölçektir. Hak-iddia etme/sömürü, gösterişçilik ve liderlik/otorite alt boyutlarından oluşan bu ölçeğin, kişilik özelliği olarak narsisizmi grandiyözite açısından ölçmesi konusunda literatüre önemli bir katkı sağlayacağı düşünülmektedir. Bu araştırma kapsamında hem ölçeğin 13 maddelik kısa formunun Türkçe'ye kazandırılması hem de klinik olmayan normal örneklem üzerinde çalışmanın yapılması önem arz etmektedir. Bu çalışma kapsamında NPI-13'nin Türkçe uyarlama çalışması gerçekleştirilmiştir.

\section{Yöntem}

\section{Çalışma Gurubu}

Araştırmanın çalışma gurubunu 2017-2018 eğitim-öğretim yılı Muğla Sıtkı Koçman Üniversitesi Eğitim Fakültesi'nin çeşitli bölümlerine devam eden öğrenciler oluşturmaktadır. Öğrencilerin 212'si kadın (\%69), 96's1 (\%31) erkektir. Katılımcıların yaşları 18 ila 67 arasında değişmektedir (Ort:21.31, Ss:3.366). Çalışma grubunun seçiminde seçkisiz olmayan, uygun örnekleme yöntemi benimsenmiştir.

\section{Veri Toplama Araçları}

NKE-13: Gentile ve arkadaşları (2013) tarafından geliştirilen ölçek, 13 maddeden ve 3 boyutlu bir yapıdan oluşmakta, derecelendirmesi 1=Tamamen katılmıyorum 6=Tamamen katılıyorum arasında değişmektedir. Ölçeğin çeşitli versiyonlarının geliştirilmesi için çeşitli yaş grupları ile çalışılmıştır. 13 maddelik versiyonunun geliştirilmesinde yaş ortalaması 33.30 olan (Ss:12.21) Amerika Birleşik Devkletlerinde yaşıyan \%48.7'si kadın, \%51.3'ü erkek olan bir örneklemden veri toplanmıştır. Ölçeğin 3 faktörlü yapısının DFA uyum indekslerinin iyi olduğu görülmüştür $(\chi 2=333.41, \mathrm{df}=62, \quad \chi 2 / \mathrm{df}=5.37$; RMSEA=0,059, SRMSR= .056, CFI=0,931). Ölçeğin bütünü için Cronbach 
Alpha değeri 82 bulunurken liderlik/otorite için .73, grandiyözite/gösterişçilik için .75 , hak iddia etme/sömürü için .52 bulunmuştur.

\section{İşlem}

NKE-13'nin uyarlama ve psikometrik çalışmalarını yapabilmek için, öncelikle, ölçeğin geliştiricilerinden mail ile izin alınmıştır. Daha sonra 2 ayrı kendi alanlarında uzman ve İngilizce Öğretimi Anabilim Dalı'nda çalışan akademisyenler tarafından maddelerin Türkçe'ye çevirisi yapılmıştır. Çevirinin ardından, rehberlik ve psikolojik danışmanlık alanında uzman tarafından ölçeğin nihai hali verilmiştir. Bu işlemin ardından yazalar tarafından ölçek maddelerinin hem İngilizcesi hem Türkçesi olan bir form ile değerlendirme formu oluşturulmuştur. Bu form kullanılarak uzmanlar tarafindan ölçeğin orijinaline uygunluğu konusunda gerekli görüş alınmış ve gerekli düzeltmeler uzman görüşlerine istinaden yapılmıştır. Uzmanlardan alınan geribildirime istinaden ölçeğin alt boyutları için; liderlik/otorite, grandiyözite/gösterişçilik, hak iddia etme/sömürü isimleri faktörleştirme tamamlanmıştır. Maddelerin son hali, madde sayısı, sıralaması ve derecelendirmesi bakımından özgün ölçekteki düzeni korunmuştur.

Bir sonraki aşamada, Türkçe Eğitimi alanında uzman ve Türkçe Eğitimi Anabilim Dalı çalışan akademisyenler tarafından maddeler incelenerek ölçeğin Türkçe formunun son hali verilmiştir. Çalışma bittikten sonra 1 İngilizce uzmanı tarafından geri-çeviri yapılmış ve elde edilen İngilizce form farklı 3 uzman tarafından incelenmiş ve orijinal ölçekle iyi derecede benzeştiği tespit edilmiştir. Tüm bu işlemlerden sonra dil geçerliliği aşaması tamamlanmıştır.

\section{Verilerin Analizi}

Verilerin analizinde, ölçek uyarlama çalışmalarında kullanılan Doğrulayıcı Faktör Analizi (DFA) yapı geçerliğini test etmek için, Cronbach Alpha analizi ise iç tutarlılığı belirlemek için güvenirlik analizinde kullanılmıştır. Açımlayıcı faktör analizi (AFA) gizil faktörlerin sayısını, modelinin veya faktörlerin ilişkisini bilemez fakat DFA ile daha önce elde edilmiş bir yapı ile ilgili bütün bilgilere sahiptir (Çelik ve Yılmaz, 2013). DFA'nın temel özelliği bir hipotezi test edebilmesidir. Aynı zamanda daha önce elde edilmiş yapının farklı bir örneklemde aynı şekilde olup olmadığını sorgulamada kullanılabilecek en 
uygun analiz DFA'dır. Analizlere başlanmadan önce veri setinde uç değer olup olmadığı kontrol edilmiştir. Bu amaçla her bir katılımcının toplam puanı hesaplanmış ve bu toplam puanlar z puanına dönüştürülmüştür. Aritmetik ortalama ve standart sapmanın kullanıldığı bir istatistik tekniğidir. Standart puan, katılımc puanının grubun puan ortalamasından olan farklarının standart kayma birimi cinsinden belirtilmesidir. Teorik olarak -3 ile +3 dışında kalan puanlar uç veri olarak kabul edilmektedir. Bu sebeple -3 ile +3 dışında z puanına sahip veriler olup olmadığına bakılmış ve bu aralık değere sahip veri olmadığ 1 görülmüştür. Verilerin analizinin tüm aşamalarında Jamovi (2019) programı kullanışmıştır. Jamovi R (2018) altyapısını ve paketlerini kullanan bir yazılımdır. Jamovi DFA için Lavaan (Rosseel vd. 2018) paketini kullanmaktadır.

\section{Bulgular}

\section{Betimsel İstatistikler}

Ölçme aracının uyarlanma çalışmasında veri ortalamaları ve standart sapmaları hesaplanmıştır. Hesaplanan değerler tablo 1'de verilmiştir.

Tablo 1. Narsistik Kişilik Envanteri-13 Değerleri

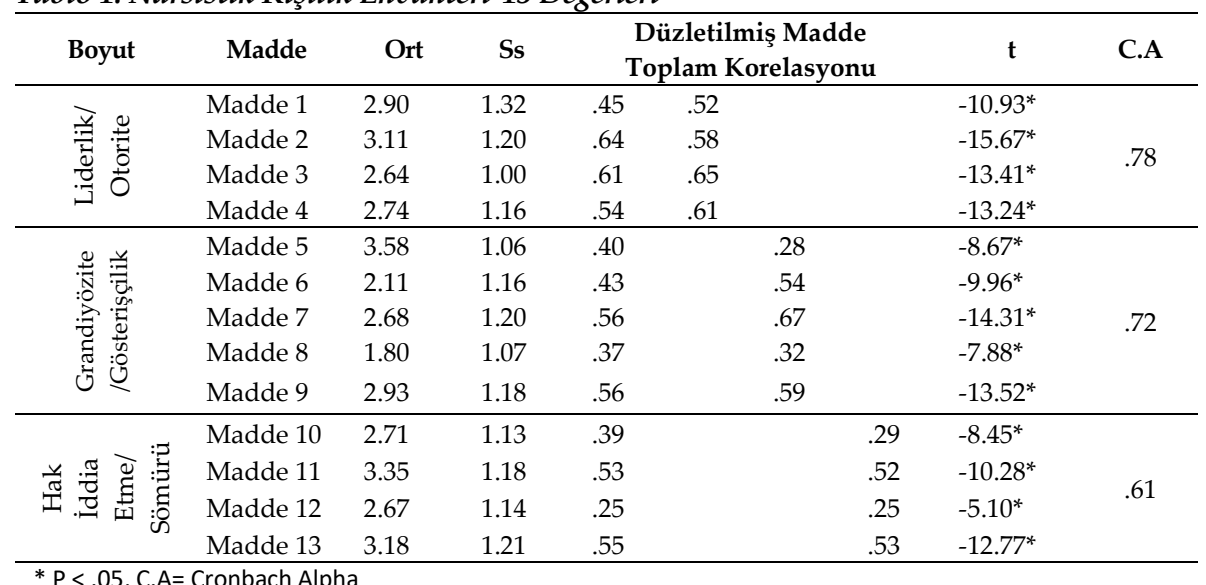

Ölçek maddelerinin ortalamaları incelendiğinde, likert tipi bir ölçek olan "geliştirilen Narsisistik Kişilik Envanteri-13" ortalamalarının en düşüğünün 
1.80 en yükseğinin 3.58 arasında değiştiği görülmektedir. Genel olarak bakıldığında ölçek maddelerinin standart sapmalarının çok büyük olmadığı da görülmektedir.

\section{Yapı Geçerliği}

Ölçeğin yapı geçerliği için DFA yapılmıştır. DFA sonucunda ölçme aracının üç faktörlü yapısı (liderlik/otorite, grandiyözite/gösterişçilik, hak iddia etme/sömürü) doğrulanmıştır. Ölçeğe ilişkin tanımlyacı istaistikler tablo 2'de verilmiştir.

Tablo 2. Tablo 1. Narsistik Kişilik Envanteri-13 DFA Değerleri

\begin{tabular}{|c|c|c|c|c|c|c|c|c|}
\hline \multirow[b]{2}{*}{ Faktör } & \multirow[b]{2}{*}{ Madde } & \multicolumn{6}{|c|}{ \%95 Güven Aralığı } & \multirow[b]{2}{*}{ S.D } \\
\hline & & Değer & $\mathrm{SH}$ & Alt Sinır & Üst Sinır & Z & $\mathrm{P}$ & \\
\hline \multirow{4}{*}{ 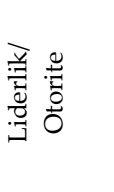 } & Madde 1 & 0.737 & 0.075 & 0.589 & 0.885 & 9.78 & $<.001$ & 0.561 \\
\hline & Madde 2 & 0.860 & 0.065 & 0.733 & 0.988 & 13.21 & $<.001$ & 0.722 \\
\hline & Madde 3 & 0.773 & 0.054 & 0.669 & 0.878 & 14.44 & $<.001$ & 0.769 \\
\hline & Madde 4 & 0.817 & 0.063 & 0.693 & 0.940 & 12.93 & $<.001$ & 0.707 \\
\hline \multirow{5}{*}{ 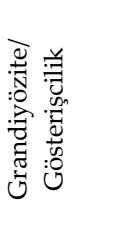 } & Madde 5 & 0.416 & 0.065 & 0.288 & 0.545 & 6.39 & $<.001$ & 0.397 \\
\hline & Madde 6 & 0.605 & 0.072 & 0.464 & 0.749 & 8.34 & $<.001$ & 0.524 \\
\hline & Madde 7 & 0.914 & 0.067 & 0.789 & 1.050 & 13.79 & $<.001$ & 0.768 \\
\hline & Madde 8 & 0.386 & 0.066 & 0.251 & 0.509 & 5.77 & $<.001$ & 0.357 \\
\hline & Madde 9 & 0.930 & 0.066 & 0.798 & 1.055 & 14.13 & $<.001$ & 0.786 \\
\hline \multirow{4}{*}{ 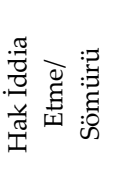 } & Madde 10 & 0.504 & 0.069 & 0.355 & 0.625 & 7.11 & $<.001$ & 0.438 \\
\hline & Madde 11 & 0.805 & 0.069 & 0.674 & 0.944 & 11.74 & $<.001$ & 0.686 \\
\hline & Madde 12 & 0.364 & 0.072 & 0.222 & 0.505 & 5.04 & $<.001$ & 0.320 \\
\hline & Madde 13 & 0.876 & 0.070 & 0.743 & 1.019 & 12.54 & $<.001$ & 0.730 \\
\hline
\end{tabular}

SH=Standart Hata, SD=Standart Değer

DFA'ya ilikin bakılması gereken bir diğer sonuç ise uyuym indeksleridir. Ölçeğin DFA'dan elde edilen uyum indeksleri incelendiğinde iyi sonuç verdiği görülmüştür $(\chi 2=130, \mathrm{df}=60, \chi 2 / \mathrm{df}=2.17$; RMSEA=0,0614, CFI=0,938; $\mathrm{TLI}=0.919$ ). Bunun yanında bütün faktör yüklerinin anlamlı ve orta seviyenin 
üstünde değerler aldığı görülmektedir. Ölçeğin DFA analizine ilişkin diğer veriler tablo 3 ‘de sunulmuştur.

Tablo 3. Narsistik Kișilik Envanteri-13 Faktör Kovayanslarn

\begin{tabular}{|c|c|c|c|c|c|c|c|c|}
\hline & & \multicolumn{7}{|c|}{$\% 95$ GA } \\
\hline & & Değer & SH & $\begin{array}{c}\text { Alt } \\
\text { Sinır }\end{array}$ & $\begin{array}{l}\text { Üst } \\
\text { Sinır }\end{array}$ & $\mathrm{Z}$ & p & SD \\
\hline \multirow[t]{3}{*}{ Liderlik/Otorite } & Liderlik/Otorite & 1.000 & & & & & & \\
\hline & Gradiyözite/Gösterişcilik & 0.585 & 0.057 & 0.474 & 0.696 & 10.321 & $<.001$ & 0.585 \\
\hline & Hak İddia Etme/Sömürü & 0.735 & 0.050 & 0.637 & 0.832 & 14.763 & $<.001$ & 0.735 \\
\hline \multirow[t]{2}{*}{$\begin{array}{l}\text { Grandiyözite/ } \\
\text { Gösterişcilik }\end{array}$} & Gradiyözite/Gösterişcilik & 1.000 & & & & & & \\
\hline & Hak İddia Etme/Sömürü & 0.622 & 0.060 & 0.505 & 0.739 & 10.449 & $<.001$ & 0.622 \\
\hline $\begin{array}{l}\text { Hak İddia } \\
\text { Etme/Sömürü }\end{array}$ & Hak İddia Etme/Sömürü & 1.000 & & & & & & \\
\hline
\end{tabular}

GA=Güven Aralığ ${ }_{1}, \mathrm{SH}=$ Standart Hata, SD=Standart Değer

Tablo 3'e bakıldığında NKE 13'ün DFA sonucunda boyutlar arasındaki faktör kovaryanslarının hesaplandığı görülmektedir. Lider/otorite ile grandiyözite/gösterişcilik arasındaki kovaryansın .58, lider/otorite ile hak iddia etme/sömürü arasındaki kovaryans .73, grandiyözite/gösterişcilik ile hak iddia etme/sömürü .62 olduğu görülmektedir.

\section{Güvenirlik Çalışması}

İç Tutarlılı̆̆ın Hesaplanması: Cronbach Alpha iç tutarlılık katsayısı, ölçeğin güvenilirliğini ortaya koymak için yapılan ilk analizdir. Analiz sonucu iç tutarlılık katsayısı ölçeğin bütünü için .84, liderlik/otorite için .78, grandiyözite/gösterişçilik için .72, hak iddia etme/sömürü için .61 bulunmuştur. Özdamara (2004)'e göre .60 ile .80 arasında olan iç tutarlılık değerleri "oldukça güvenilir", .81 ve üstü değerleri mükemmel ele almaktadır.

Alt-Üst Grup Güvenirliği: Ölçeğin güvenirliği belirlemek için yapılan bir diğer işlem alt \% 27 ile üst \% 27 `lik grupların arasındaki farka bakmaktır. Ölçekten ele edilen toplam puana göre üst puanlara sahip \%27'lik grup ile alt puanlara sahip \% 27'lik grupların farklı olması beklendiği için grupların madde ortalama puanları arasında da anlamlı bir fark olması beklenmektedir. Büyüköztürk (2007)'e göre, ölçeğin güvenirliğini gösteren bir kriter de alt 
ve üst grupların maddelere verdikleri yanıtlar arasında fark olmasıdır. Araştırma grubunun üst \%27 (N:83) ile alt \%27 (N:83) grupların ölçek maddelerinin puan ortalamaları arasındaki farkı belirlemek için t-testi yapılmıştır. Yapılan analiz göre alt ve üst grubun maddlere verdikleri cevap ortalamaları arasında anlamlı $(\mathrm{p}<$. 001) istatistiksel olarak anlamlı bir farkın olduğu görülmüştür. Bu sonuçla ilgili olarak maddelerin iyi bir ayırt ediciliğe sahip oldukları belirtilebilir. Analize ilişkin t değerleri tablo 1'de verilmiştir.

Madde Toplam Korelasyon: Bu yöntem her madde ile ölçek puanı arasındaki korelasyon katsayısının hesaplanmasına dayanır. Herhangi bir maddede korelasyon katsayısının işareti eksi, değeri sıfır veya sıfıra yakınsa bu durum, maddenin diğer maddelerin ölçmek istediği tutumu ölçmeye uzak olduğunu gösterir. Aynı şekilde ölçeği oluşturan her maddenin birbiriyle olan ilişkisinin yüksek olması da önemlidir. Maddelerin ölçek puanlarıyla ve birbirleriyle yüksek korelasyonlara sahip olmaları aynı boyutta ölçme yaptıklarını gösteren bir durumdur (Ghiselli, Campbell, Zedeck, 1981; akt. Tezbaşaran, 1996). Bu ölçeğin AFA sonuçlarına göre madde toplam korelasyonları ise 0.28 ile 0.67 arasında değişmektedir. Analize ilişkin değerler tablo 1'de verilmiştir.

\section{Sonuç ve Tartışma}

Bu çalışmada Gentile ve arkadaşları (2013) tarafından geliştirilen Narsisistik Kişilik Envanteri-13'nin Türkçe versiyonun psikometrik özelliklerinin belirlenmesi hedeflenmiştir. Ölçeğin yapı geçerliği için yapılan DFA sonucunda uyum indeksleri göz önünde bulundurulduğunda ölçeğin üç boyutlu yapıs1nın kabul edilebilir düzeyde sonuçlar verdiği $(\chi 2=130, \mathrm{df}=60, \chi 2 / \mathrm{df}=2.17$; RMSEA=0,0614, CFI=0,938; TLI=0.919) ve ölçeğin orijinal yapısının Türkçe versiyonunun yapısıyla uyuştuğu görülmektedir. Ölçeğin iç tutarlılık katsayısının oldukça güvenilir bulunması (.84) ölçeğin Türkçe yapısının güvenilir olduğunu göstermektedir.

NKE-13 grandiyöz narsisizmi ölçen bir ölçme aracıdır. Yakın zamanın literatürüne bakıldığında Narsisizm normal ve patolojik olmak üzere ikiye ayrilırken grandiyözite her ikisinde de ortak bir özellik olarak görülebilmektedir. Narsisistik Grandiyözite aşırı değer verilme, hak edilmiş benlik imgesi, sömürücü, teşhirci davranışlar idealize edilmiş fantezileri içe alma ve farklı uyumsuz kendini geliştirme stratejileriyle tanımlanır. Patolojik narsisizm 
önemli bozukluklarla ilişkiliyken normal narsisizm uyumlu olmayan işleyişi, başarı motivasyonunu ve hrsları destekleyebilir (Pincus ve Lukowitsky, 2010). Narsisitik kişilik bozukluğu ve kişilik özelliklerindeki bozulma diğer kişilik bozukluklarındakinden daha farklı ve karmaşık bir yapıdadır. Her ikisinde de açıkça kişilerarası boyutta bozulma söz konusudur. Narsisistik bireyler öz saygılarında ve statülerinde artışı toplumsal anlamda baskın olma ve statü davranışları, bilişleri, ve duyguları yoluyla arayacaktır (Miller ve Campell, 2010). Bu bilgilerden hareketle toplumda görülme sıklığı artış gösteren narsisistik kişilik yapısını ölçen ölçme araçlarına ihtiyacın her geçen gün arttığ1 söylenebilir. Kısa ölçeklerin güvenirliği konusundaki endişelere rağmen NKE-13, 40 maddelik uzun formu, narsisizm ve narsisizmle ilişkili özellikleri ölçen ölçekler, ve psikopati, histronik kişilik bozukluğu gibi yakın bozuklukları ölçen ölçeklerle güçlü korelasyonlara sahiptir (Gentile vd., 2013).

Türkçe'de narsisizmi ölçmek için kullanılan çeşitli ölçme araçları bulunmasına rağmen, yeterli olmadığı görülmektedir. Atay (2009)'un Türkçe'ye kazandırdığı, NKE-40'dan yola çıkılarak geliştirilen NKE-16 orijinal formu tek boyutlu olup, Türkçe uyarlama çalışması örgütsel süreçlerde narsisizmi ölçmeye yönelik olarak uyarlanmıştır. NKE-13, 40 maddelik uzun formun sahip olduğu üç alt boyutu da içeren, uygulama açısından kolaylık sağlayan bir ölçek olarak değerlendirilmiştir (Gentile vd., 2013).

Yapılan çalışma sonucunda NKE-13 liderlik/otorite, grandiyözite/ gösteriş̧̧ilik, hak iddia etme /sömürü olmak üzere 3 at boyuttan oluşan, geçerli ve güvenilir, Türkçe kullanıma uygun bir ölçme aracı olarak kabul edilebilir. 


\title{
EXTENDED ABSTRACT
}

\section{The Turkish Adaptation of Narcissistic Personality Inventory-13 Scale: The Validity and Reliability Study}

\author{
Uğur Doğan - Tuğba Seda Çolak \\ Muğla Sıtkı Koçman Üniversitesi- Düzce Üniversitesi
}

Narcissism is among the personality disorders in the Diagnostic and Statistical Handbook of Mental Disorders (DSM) 5. Narcissistic personality disorder has a pattern that emerges in the early stages of adulthood and includes the lack of empathy, needs for growth, and appreciation (American Psychiatric Association, 2013).

In recent years, Narcissism has been started to be considered as a personality trait as well as an element of pathology (Demirci \& Eksi, 2017). According to the characteristics that separate the narcissistic personality structure from the personality disorder, individuals in the narcissistic personality structure can stand up to criticism, and act in their purposes, not exploitative in their interpersonal relationships. They market their thoughts well, they like to compete and they see themselves as the most successful. Although they think they have a unique quality, they do not expect privilege. They can empathize and expect others to always treat them well (Köroğlu \& Bayraktar, 2010). It is likely that narcissistic features increase the desire for success and enable others to survive in discouraging situations (Lelord and Andre, 2015). At the same time, a positive relationship was found between Narcissism and self-esteem (Karakuş, 2017).

Although some scales measure Narcissism as a personality trait, they are limited, and mostly these scales are not suitable for normal sample people. Therefore new and reliable scales in Turkish are needed. This study aims to adapt NPI-13 to Turkish, and it is essential because the study group consists of normal sample.

The study group of the research consists of students who are educated in various programs of Muğla Sitkı Koçman University Education Faculty in 2017-2018. $212(69 \%)$ of the students are female, 96 (31\%) of them are male. 
The ages of participants ranged from 18 to 67 (Avg: 21.31, SD: 3.366). While the study group was being determined, convenience sampling, which is not random, was used.

NPI-13: The scale was developed by Gentle et al. (2013) consists of 13 items and a 3 dimentional structure. CFA fit indices of the 3 factor structure of the scale were found to be good $(\chi 2=333.41, \mathrm{df}=62, \chi 2 / \mathrm{df}=5.37$; RMSEA=0,059, $\mathrm{SRMSR}=.056, \mathrm{CFI}=0,931)$. The Cronbach Alpha value for the whole scale wa .82 , while it was .73 for leadership/ authority, .75 for grandiose/ exhibitionism, .52 for entitlement/ exploitativeness.

In the analysis of the data, confirmatory factor analysis (CFA) was used to test construct validity, and the Cronbach alpha internal consistency was used şn the reliability analysis. Jamovi (2019) program was used in all stages of data analysis.

Descriptive Statistics: When the averages of the scale items are examined, it is seen that averages of the "Narcissistic Personality Inventory-13", which is a Likert type scale, range between the lowest 1.80 and the highest 3.58 . In general, it can be seen that the standard deviations of the scale items are not very large.

Construct Validity: When the fit indexes of the analysis are analyzed, it is seen that it gives good results $(\chi 2=130, \mathrm{df}=60, \chi 2 / \mathrm{df}=2.17$; RMSEA $=0.0614$, $\mathrm{CFI}=0.938 ; \mathrm{TLI}=0.919)$. In addition, all factor loads appear to have significant and above-average levels.

As a result of the CFA of the NPI-13, the covariance between Leadership/ authority and grandiose/ exhibitionism dimensions is .58, covariance between leadership / authority and entitlement/ exploitativeness dimensions is .73, covariance between grandiose/ exhibitionism and entitlement/ exploitativeness dimensions is .62 .

As a result of the analysis, the internal consistency coefficient Cronbach Alpha was .84 for the whole scale, .78 for leadership/authority, .72 for grandiose/ exhibitionism, and .61 for entitlement/ exploitativeness.

The t-test was performed for the significance of the differences between the item mean scores of the upper $27 \%(\mathrm{~N}: 83)$ and lower $27 \%(\mathrm{~N}: 83)$ groups taken from the study population. As a result of the $\mathrm{t}$-test performed according to the average results of the groups, a significant difference $(p<.001)$ was found between the lower and upper groups. Regarding this result, it can be stated that the items have good discrimination. 
According to the EFA results of this scale, item-total correlations vary between 0.28 and 0.67 .

In this study, it was aimed to determine the psychometric properties of the Turkish version of the Narcissistic Personality Inventory-13 developed by Gentile et al. (2013). Considering the compliance indexes of the CFA for the construct validity of the scale, the three-dimensional structure of the scale gives acceptable results $(\chi 2=130, \mathrm{df}=60, \chi 2 / \mathrm{df}=2.17$; RMSEA $=0.0614, \mathrm{CFI}=$ 0.938; TLI $=0.919$ ) and the original structure of the scale seems to match the structure of the Turkish version. The fact that the internal consistency coefficient of the scale is quite reliable (.84) shows that the Turkish structure of the scale is reliable.

NPI-13 is a measurement tool that measures grandiose Narcissism. Looking at the recent literature, Narcissism is divided into two as normal and pathological, while Grandiosity can be seen as a standard feature in both. Narcissistic Grandiosity is defined by overvaluation, deserved self-image, exploitative, exhibitionist behaviors, strategies to include idealized fantasies and different incompatible self-development. While pathological Narcissism is associated with essential disorders, healthy Narcissism can support incompatible functioning, motivation for success, and ambitions (Pincus and Lukowitsky, 2010). Narcissistic personality disorder and impairment in personality traits are different and complicated than other personality disorders. Both are clearly impaired in the interpersonal dimension. Narcissistic individuals will seek an increase in their self-esteem and status through social dominance and status behavior, cognition, and emotions (Miller \& Campell, 2010). Based on this information, it can be said that the need for measuring tools that measure the narcissistic personality structure, which has an increasing frequency in the society, increases day by day. Despite concerns about the reliability of short scales, NPI-13 has strong correlations with its long-form of 40 items, scales Narcissism and measuring properties related to Narcissism, and scales measuring close disorders such as psychopathy and histrionic personality disorder (Gentile et al., 2013).

\section{Kaynakça}

Amerikan Psikiyatri Birliği (2013). Ruhsal bozuklukların tanısal ve sayımsal elkitabı (DSM-5) tanı ölçütleri başvuru elkitabı (Çev. E. Köroğlu). Ankara: HYB Yayıncilik 
Ames, D. R., Rose, P. ve Anderson, P.C. (2006). The NPI-16 as a short measure of narcissism. Journal of Research in Personality, 40, 440-450.4

Anlı, İ., Can, Y. ve Evren, C. (2017). Erkek Alkol Kullanım Bozukluğu Hastalarında Patolojik Narsisizmin Erken Dönem Uyumsuz Şemaların Gelişimi Üzerindeki Etkisi. Psikiyatride Güncel Yaklaşımlar, 9(1), 63-74. doi:10.18863/pgy.281127

Aslan, M., Mert, H.Ş ve Yıldız, M. (2016). Narsistik kişilik ile affedicilik arasındaki ilişkinin incelenmesi. 2. Uluslararası Çin'den Adriyatik'e Sosyal Bilimler Kongresi, Hatay, Türkiye.

Atay, S. (2009). Narsistik kişilik envanteri'nin Türkçe'ye standardizasyonu. Gazi Üniversitesi İktisadi ve İdari Bilimler Fakültesi Dergisi, 11 (1), 181-196.

Back, M. D., Küfner, A. C., Dufner, M., Gerlach, T. M., Rauthmann, J. F., ve Denissen, J. J. (2013). Narcissistic admiration and rivalry: Disentangling the bright and dark sides of narcissism. Journal of Personality and Social Psychology, 105(6), 1013.

Büyükgüngör, A. (2016). The Turkish adaptation of the pathological narcissism ınventory. Yüksek Lisans Tezi. Bahçeşehir Üniversitesi, İstanbul.

Campbell, W.K. ve Foster, C.A. (2002). Narcissism and commitment in romantic relationships: An investment model analysis. Personality and Social Psychology Bullettin, 28, 484-495. DOI: 10.1177/0146167202287006

Demirci, İ. ve Ekşi, F. (2017). Büyüklenmeci narsisizmin iki farklı yüzü: Narsisistik hayranlık ve rekabetin mutlulukla illişkisi.Marmara Üniversitesi Atatürk Eğitim Fakültesi Eğitim Bilimleri Dergisi, 46,37-58. DOI:10.15285/maruaebd.330008

Ekşi, F. (2016). The short form of the Five-Factor narcissism inventory: Psychometric equivalence of the Turkish version. Educational Sciences: Theory $\mathcal{E}$ Practice, 16, 1081-1096. http://dx.doi.org/10.12738/estp.2016.4.0001

Gentile, B., Miller, J.D., Hoffman, B.J., Reidy, D.E., Zichner, A., ve Campbell, W.K. (2013). A test of two brief measures of grandiose narcissism: The narcissistic personality inventory-13 and the narcissistic personality inventory-16. Psychological Assessment, 25(4), 1120-1136. DOI: 10.1037/a0033192

Glover, N., Miller, J. D., Lynam, D. R., Crego, C., ve Widiger, T. A. (2012). The Five-Factor Narcissism Inventory: A five-factor measure of narcissistic personality traits. Journal of Personality Assessment, 94, 500-512. http://dx.doi.org/10.1080/00223891.2012.670680 
Karakuş, Ç. (2017). Lise öğrencileerinde psikolojik savunmalar açısından narsisizm ve benlik saygısının karşılaştırılması. İstanbul Sabahattin Zaim Üniversitesi, Yüksek Lisans Tezi, İstanbul.

Kohut, H.(1998). Kendiliğin çözümlenmesi. İstabul: Metis Yayınları

Konrath, S., Brian, P.M., ve Bushman, B.J. (2014). Development and validation of the Single Item Narcissism Scale (SINS). PLoS ONE, 9, 8.

Kotan, V.O., Kotan, Z. ve Özçürümez-Bilgili, G. (2018). Psikanalitik ilkeleri temel alan tanısal sinıflandırma Sistemleri. Nöropsikiyatri Arşivi, 55, 91-97. https://doi.org/10.29399/npa.19505

Köroğlu, E. ve Bayraktar, S. (2010). Kişilik bozuklukları. Ankara: HYB Yayıncılık.

Lelord,F.ve Andre, C. (2015)."Zor kişilikler"le yaşamak(24.bask1).İstanbul:İetişim Yayınları

Masterson, J.F. (2014). Gerçek kendilik: Gelişimsel kendilik ve nesne ilişkileri yaklaşımı. İstanbul: Psikoterapi Enstitüsü Yayınları.

Miller, J. D., ve Campbell, W. K. (2010). The case for using research on trait narcissism as a building block for understanding narcissistic personality Disorder. Personality Disorders: Theory, Research, and Treatment, 1(3), 180191. DOI: $10.1037 / \mathrm{a} 0018229$

Özdamar, K. (2004). Paket programlar ile istatistiksel veri analizi-II, (Çok değişkenli Yöntemler), 5. Baskı. Eskişehir: Kaan Kitabevi.

Özsoy, E., Rauthmann, J.F., Jonason, P.K., ve Ardıç, K. (2017). Reliability and validity of the Turkish versions of Dark Triad Dirty Dozen (DTDD-T), Short Dark Triad (SD3-T), and Single Item Narcissism Scale (SINS-T). Personality and Individual Differences, 117, 11-14. doi: 10.1016/j.paid.2017.05.019

Pincus, A. L. ve Lukowitsky, M. R. (2010). Pathological narcissism and narcissistic personality disorder. Annual Review of Clinical Psychology, 6, 421-446. doi: 10.1146/annurev.clinpsy.121208.131215.

R Core Team (2018). R: A Language and envionment for statistical computing. [Computer software]. Retrieved from https://cran.r-project.org/.

Rosseel, Y., vd. (2018). lavaan: Latent Variable Analysis. [R package]. Retrieved from https://cran.r-project.org/package=lavaan.

The jamovi project (2019). jamovi. (Version 1.0) [Computer Software]. Retrieved from https://www.jamovi.org.

Thomaes, S., Bushman, B. J., Denissen, J., Stegge, H. ve Olthof, T. (2008). Development And Validation Of The Childhood Narcissism Scale. Journal of Personality Assessment, 90, 382-391. 
Volkan, V. (2007).Psikoterapide nesne ilişkileri: Nörotik, narsisistik, sınırda ve psikotik hastaların tedavisinde nesne ilişkileri pratĭ̆i.İzmir:Odağ Psikanaliz ve Psikoterapi

Voltan-Acar, N. (2012). Psikolojik danışma ve rehberlik sözlüğü Ingilizce/Türkçe (1. bask1). Ankara: Nobel yayın

Wallace, E.R. (2008). Dinamik psikiyatri kuramı ve uygulaması (Çev. H. Atalay). İstanbul: Okuyan Us Yayınları.

Williams, N. (2013). Psikanalitik tanı: Klinik süreç içinde kişilik yapısını anlamak. İstanbul: Bilgi Üniversitesi Yayınları

Yeomans, F.E., Clarkin, J.F., ve Kernberg, O.F. (2016). Borderline Kişilik Bozukluğu için Aktarım Odaklı Psikoterapi. İstanbbul: Psikoterapi Enstitüsü Yayınları.

\section{Ek 1. Ölçek Maddeleri}

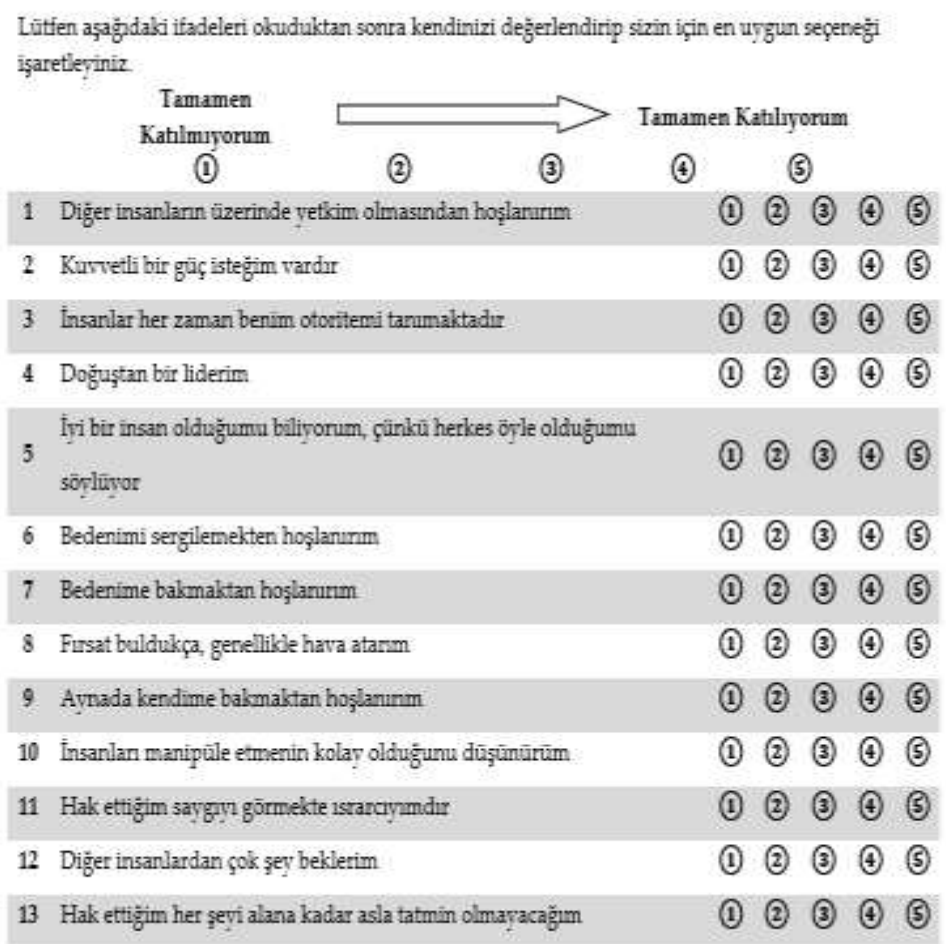




\section{Kaynakça Bilgisi / Citation Information}

Doğan, U. ve Çolak, T. S. (2020). Narsisistik kişilik envanteri-13 (NKE13)'nin Türkçe geçerlik ve güvenirlik çalışması. OPUS-Uluslararası Toplum Araştırmaları Dergisi, 15(26), 4166-4184. DOI: 10.26466/opus.635725 